\title{
Knowledge, Attitude and Practice towards Vitamin D Importance and Supplementation among Mothers of under Five Children in a Primary Health Care Center in Cairo
}

\author{
Nadia S Soliman, Maha M Wahdan, Nahla F Abouelezz, Sahar M Sabbour
}

Community, Environmental and Occupational Medicine Department, Faculty of Medicine, Ain Shams University.

\begin{abstract}
Background: Vitamin D deficiency is a pandemic especially in women in childbearing age mainly due to lack of awareness about the importance of vitamin $\mathrm{D}$ and prevention of its deficiency. Objective: To assess the knowledge, attitude and practice of mothers attending primary health care center in Cairo towards vitamin D, its supplementation \& sun light exposure. Methods: A cross sectional study was conducted on 195 mothers attending a primary health care center in El-Sherouk city in Cairo using structured questionnaire including sociodemographic data, mother's knowledge, attitude and practice towards the importance of Vitamin D, its supplementation and sun light exposure for herself and her child and a scoring system was designed. Results: Less than one quarter of the mothers (22.6\%) had a good knowledge (total knowledge score percentage $>50 \%$ ). Thirty six percent $(36 \%)$ of mothers had a positive attitude (total attitude score percentage $\geq 75 \%) \&$ forty-six $(46 \%)$ percent of mothers had a good practice (total practice score percentage $\geq 75 \%$ ). About $53.5 \%$ of mothers were exposed to the sun from 10 am to $3 \mathrm{pm}$, and $91.1 \%$ were exposed to the sun more than one hour per week. Only $48.7 \%$ of the mothers gave their children vitamin D supplementation. Conclusion \& recommendation: Less than one quarter of the mothers had a good knowledge while about three fifths of the mothers had a positive attitude \& less than half of them had a good practice towards vitamin D and its supplementation. Awareness campaigns may help in improving awareness about vitamin $\mathrm{D}$ importance.
\end{abstract}

Key words: Vitamin D, Deficiency, Sun exposure, Awareness, Mothers.

Corresponding author: Maha Magdy Wahdan; drmaha_wahdan@med.asu.edu.eg

\section{Introduction}

Vitamin D deficiency is a major public health problem worldwide in all age groups. ${ }^{1,2}$ Approximately one billion people worldwide are estimated to be vitamin D deficient with people living in Europe, the Middle East, China and Japan at particular risk. $^{3}$

Fuleihan reported that hypo-vitaminosis D is prevalent across all life stages with deleterious immediate and latent manifestations. ${ }^{4}$ It is also reported by Palacios \& Gonzalez as a global problem particularly in girls and women in the Middle East. ${ }^{2}$ During pregnancy, previous studies have reported the prevalence of Vitamin D deficiency ranges from 18-84\%, depending on the country of residence and local clothing customs. ${ }^{5,6}$

Mrad et al., 2009 conducted a study among sample of Tunisian mothers revealed that $47.5 \%$ of the mothers did not know the action of vitamin D and only $68 \%$ of their infants had received vitamin $\mathrm{D} .^{7}$

Oct. 
Table (1): Characteristics of mothers and their children attending primary health care center in Cairo (n =195)

\begin{tabular}{|c|c|c|c|}
\hline Variables & Mean \pm SD & $\begin{array}{c}\text { Number } \\
\text { (No.) }\end{array}$ & $\begin{array}{c}\text { Percent } \\
(\%)\end{array}$ \\
\hline Mother's age in years & $30.1 \pm 4.7$ & & \\
\hline Less than 25 & & 21 & 10.8 \\
\hline $25-$ & & 65 & 33.3 \\
\hline $30-$ & & 72 & 36.9 \\
\hline 35 or more & & 37 & 19.0 \\
\hline \multicolumn{4}{|l|}{ Number of Children of mother } \\
\hline One & & 56 & 28.7 \\
\hline Two & & 79 & 40.5 \\
\hline Three & & 44 & 22.6 \\
\hline Four or more & & 16 & 8.2 \\
\hline \multicolumn{4}{|l|}{ Children under five } \\
\hline One & & 136 & 69.7 \\
\hline Two & & 56 & 28.8 \\
\hline Three & & 3 & 1.5 \\
\hline Child age in months (youngest child) & $22 \pm 17.3$ & & \\
\hline $1-12$ & & 87 & 44.6 \\
\hline$>12$ & & 33 & 16.9 \\
\hline 24- & & 37 & 19.0 \\
\hline $36-$ & & 24 & 12.3 \\
\hline $48-60$ & & 14 & 7.2 \\
\hline \multicolumn{4}{|l|}{ Mother's educational status } \\
\hline Illiterate/Read and write & & 15 & 7.7 \\
\hline Primary /Preparatory & & 14 & 7.2 \\
\hline Secondary & & 25 & 12.8 \\
\hline University/ Profession & & 141 & 72.3 \\
\hline \multicolumn{4}{|l|}{ Mother's occupational status } \\
\hline Housewife & & 101 & 51.8 \\
\hline Working & & 94 & 48.2 \\
\hline \multicolumn{4}{|l|}{ Status of housing } \\
\hline Owned & & 123 & 63.1 \\
\hline Rented & & 72 & 36.9 \\
\hline \multicolumn{4}{|l|}{ Family income } \\
\hline Less than $1000 \mathrm{LE}$ & & 12 & 6.1 \\
\hline 1000 to $2000 \mathrm{LE}$ & & 58 & 29.7 \\
\hline$>2000$ to $4000 \mathrm{LE}$ & & 43 & 22.1 \\
\hline More than $4000 \mathrm{LE}$ & & 82 & 42.1 \\
\hline
\end{tabular}

In Egypt, over the last two decades, accumulating data on the vitamin D status indicate increasing the prevalence of vitamin $\mathrm{D}$ deficiency among healthy members of the population ${ }^{8}$, particularly mothers and their neonates. ${ }^{9}$ It was indicated that between $25.7 \%$ and $77.2 \%$ of
Egyptian infants and women (pregnant and non-pregnant) had vitamin D inadequacy. ${ }^{10}$ Several studies from different parts of the world show that knowledge, attitude and behavior play an important role in influencing the major risk factors leading to 
Table (2): mothers' knowledge about Vitamin D and source of knowledge:

\begin{tabular}{|c|c|c|}
\hline Knowledge statements & Number (No.) & Percent (\%) \\
\hline \multicolumn{3}{|l|}{ Heard about vitamin D } \\
\hline No & 25 & 12.8 \\
\hline Yes & 170 & 87.2 \\
\hline \multicolumn{3}{|l|}{ Sources of knowledge $\uparrow$} \\
\hline Family/friends & 38 & 22.4 \\
\hline Physician & 106 & 62.4 \\
\hline School/university & 30 & 17.6 \\
\hline Media (TV /Radio/ Internet) & 79 & 46.5 \\
\hline \multicolumn{3}{|l|}{ Vitamin D benefits $\dagger$} \\
\hline Bone health $*$ & 154 & 90.6 \\
\hline Enhance immunity* & 65 & 38.9 \\
\hline Healthy pregnancy* & 36 & 21.2 \\
\hline Prevent arthritis* & 30 & 17.6 \\
\hline Prevent stroke* & 20 & 11.8 \\
\hline Heart health* & 12 & 7.1 \\
\hline Prevent hypertension* & 9 & 5.3 \\
\hline Prevent diabetes* & 7 & 4.2 \\
\hline Don't know & 5 & 2.9 \\
\hline Hair health & 3 & 1.8 \\
\hline Prevent depression* & 2 & 1.2 \\
\hline Prevent obesity* & 2 & 1.2 \\
\hline Skin health & 2 & 1.2 \\
\hline \multicolumn{3}{|l|}{ Sources of vitamin D +} \\
\hline Sun & 143 & 84.1 \\
\hline Food & 104 & 61.2 \\
\hline Supplementation & 29 & 17.1 \\
\hline Don't know & 8 & 4.7 \\
\hline \multicolumn{3}{|c|}{ Sources of food containing vitamin $\mathrm{D} \dagger$} \\
\hline Milk and dairy products* & 70 & 67.3 \\
\hline Egg yolk* & 64 & 61.5 \\
\hline Oily fish* & 55 & 52.9 \\
\hline Fruits & 31 & 29.8 \\
\hline Vegetables & 31 & 29.8 \\
\hline Liver* & 15 & 14.4 \\
\hline
\end{tabular}

*correct answer, + Participants gave more than one answer, so the percentages did not add up to $100 \%$

vitamin D deficiency or insufficiency. $7,11,12,13,14,15,16,17$

So, this study was conducted with the aim to assess the knowledge and attitude of mothers attending primary health care center in Cairo towards vitamin D importance, to identify mothers' practices towards vitamin D and its supplementation and to identify mothers' practices towards sun light exposure.

\section{Methods}

Study Design: A cross sectional study was conducted at primary health care center at El Sherouk city. Study Population: Convenience sample of Mothers attending the primary health care center were enrolled. The researcher chose two days at random and interviewed mothers of under five children attending in these two days according to their availability and who agreed to participate in the study.

\begin{tabular}{lllll}
\hline The Egyptian Journal of Community Medicine & Vol. 38 & No. 4 & Oct. & 2020
\end{tabular} 
Table (3): Mothers' attitude towards vitamin D and its supplementation:

\begin{tabular}{lrr}
\hline Variables & $\begin{array}{l}\text { Number } \\
(\text { No. })\end{array}$ & $\begin{array}{l}\text { Percent } \\
(\boldsymbol{\%})\end{array}$ \\
\hline Are you in favor of taking vitamin & D \\
supplementation during pregnancy? & \\
\hline Agree & 111 & 56.9 \\
Neutral & 65 & 33.3 \\
Disagree & 19 & 9.8 \\
\hline
\end{tabular}

Are you in favor of taking vitamin $D$ supplementation during lactation?

\begin{tabular}{lrr}
\hline Agree & 120 & 61.5 \\
Neutral & 56 & 28.7 \\
Disagree & 19 & 9.8 \\
\hline
\end{tabular}

Are you in favor of using sunscreen while exposing to the sun?

\begin{tabular}{lll}
\hline Agree & 92 & 47.2 \\
Neutral & 65 & 33.3 \\
Disagree & 38 & 19.5 \\
\hline
\end{tabular}

Are you in favor of doing a test for you to know level of vitamin $D$ in the blood?

\begin{tabular}{lrr}
\hline Agree & 134 & 68.7 \\
Neutral & 48 & 24.6 \\
Disagree & 13 & 6.7 \\
\hline
\end{tabular}

Are you in favor of giving vitamin D supplementation to your child since birth?

\begin{tabular}{lrr}
\hline Agree & 150 & 76.9 \\
Neutral & 31 & 15.9 \\
Disagree & 14 & 7.2 \\
\hline
\end{tabular}

Are you in favor of exposing your child to sun rays?

\begin{tabular}{lrr}
\hline Agree & 176 & 90.3 \\
Neutral & 15 & 7.6 \\
Disagree & 4 & 2.1 \\
\hline
\end{tabular}

Sample Size: Sample of 195 mothers was calculated using Epi-info program version 7 using the frequency of knowledge about the action of vitamin D (54.3\%). ${ }^{10}$ Accepted range was (47\%-61\%) at $95 \%$ C.I.

Study Tools: An interview questionnaire was adopted from previous studies Cinar et al., 2006, Kavitha et al., 2015, and Kamal et al., $2017^{23,24,27}$ and it was used to collect information about: Section I: Sociodemographic characteristics of the studied mothers e.g. (age, parity, education, occupation, family income, child age, child sex). Section II: Information related to the participant's knowledge about the importance of Vitamin D, the source(s) of their knowledge about vitamin D, knowledge about the problems associated with vitamin D deficiency and sources of vitamin D. Section III: Information related to the participant's attitude towards vitamin $\mathrm{D}$ and its supplementation (through asking the mothers about their attitude towards taking vitamin D supplementation during pregnancy and lactation, exposing their children to direct sunlight, giving them vitamin D supplement since birth ,tendency to use of sun blocks). Section IV: Information related to the participant's practice towards vitamin D supplementation and sun light exposure (through asking the mothers about intake of vitamin D supplements during pregnancy and lactation, time of exposure to sun light ,parts of body exposed to the sun, using sun screen while exposing to the sun). Also, information related to the mother's practice towards her youngest child (through asking about sun exposure, nutrition of her child and her compliance with giving her child vitamin D supplements).

Content Validity of the questionnaire: The clarity, relevance, comprehensiveness, and applicability of the questionnaire were evaluated by Staff experts from Public Health Specialty, Faculty of Medicine; Ain shams University. And according to their comments, some modifications were done.

Pilot Study: The designed questionnaire was tested on 15 mothers before data collection. Data obtained from the pilot study was excluded from the analysis. Clarity of the questions in the questionnaire were assessed and modified by adding examples for more clarity, change questions, new response categories were added to some questions; also, Time required to complete the collection of data

Oct.

2020 
Table (4): Mothers' practice towards vitamin D intake and sun exposure

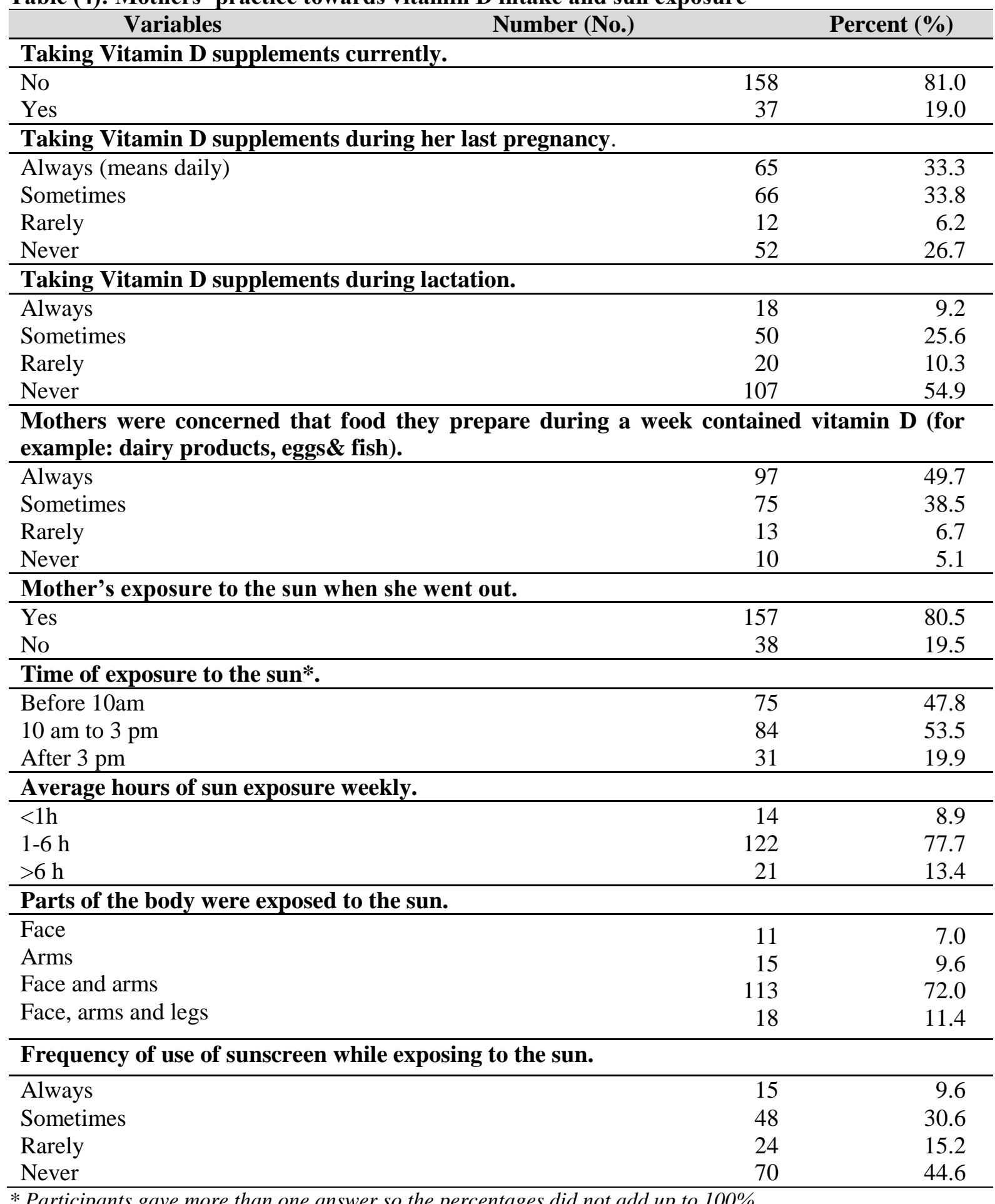

* Participants gave more than one answer so the percentages did not add up to $100 \%$.

was determined which is about $10-15$ minutes.

Health Education flyers designed by the researcher were used to deliver a concise targeted health education message about vitamin $\mathrm{D}$ sources and its importance to all the interviewed mothers after the interview. Operational definition of adequate sun light exposure: Exposure to the sun rays is

\begin{tabular}{lllll}
\hline The Egyptian Journal of Community Medicine & Vol. 38 & No. 4 & Oct. & 2020
\end{tabular}


Table (5): Mothers' practice towards their children regarding vitamin $D$ and its supplementation:

\begin{tabular}{lrr}
\hline \multicolumn{1}{c}{ Variables } & $\begin{array}{c}\text { Number } \\
(\text { No. })\end{array}$ & $\begin{array}{r}\text { Percent } \\
(\%)\end{array}$ \\
\hline Exposing the child to the Sun. $*$ & \\
\hline No & 30 & 15.4 \\
Yes & 165 & 84.6 \\
\hline Parts of the child body were exposed to the \\
sun. $\dagger$ \\
\hline Face & 131 & 79.4 \\
Arms & 115 & 69.7 \\
Legs & 106 & 64.2 \\
Whole body & 17 & 10.3 \\
\hline
\end{tabular}

Time of exposure of child body to the sun light. $\dagger$

\begin{tabular}{lll}
\hline Before 10 am & 99 & 60.0 \\
10 am to 3 pm & 59 & 35.8 \\
After 3 pm & 35 & 21.2 \\
\hline
\end{tabular}

Average hours of sun exposure to child weekly.

\begin{tabular}{|c|c|c|}
\hline$<1 \mathrm{~h}$ & 26 & 15.8 \\
\hline $1-6 \mathrm{~h}$ & 120 & 72.7 \\
\hline$>6 \mathrm{~h}$ & 19 & 11.5 \\
\hline $\begin{array}{l}\text { Giving the child } \\
\text { Supplementation. }\end{array}$ & vitamin & D \\
\hline No & 100 & 51.3 \\
\hline Yes & 95 & 48.7 \\
\hline
\end{tabular}

Giving the child vitamin D drops regularly (Every day, 400IU to 600IU).

\begin{tabular}{lrr}
\hline Always & 49 & 51.6 \\
Sometimes & 42 & 44.2 \\
Rarely & 3 & 3.2 \\
Never & 1 & 1.1 \\
\hline
\end{tabular}

If not always, Causes.

\begin{tabular}{lrr}
\hline Forget & 38 & 82.6 \\
child illness & 4 & 8.7 \\
Not concerned & 2 & 4.3 \\
Physician & 1 & 2.2 \\
Food and sun & 1 & 2.2 \\
dependence & &
\end{tabular}

* Exposing child to the sun either in home or outside,

+ Participants gave more than one answer, so the percentages did not add up to $100 \%$.

considered adequate if it is more than twice per week exposure of arms and legs which is equivalent to $20-25 \%$ body surface area between 10 am to 3 pm. ${ }^{18}$ Also, WHO has recommended that 5-15 min of casual sun exposure two to three times a week during the summer months is sufficient to keep vitamin $\mathrm{D}$ at optimal level. ${ }^{19}$ The duration increases up to 3 times among individuals with dark skin pigmentation \& 6 times among individuals with very dark skin pigmentation as much exposure as light skinned individuals. ${ }^{20}$

\section{Data Management and Analysis}

The collected data was revised, coded, tabulated and introduced to personal computer then analyzed using SPSS program (Statistical Package for Social Sciences) for windows Version 22. Qualitative data were presented as frequencies and percentages, while quantitative variables were presented as mean, standard deviation (SD). Independent $\mathrm{T}$ test, ANOVA test and Post HOC test were used as tests of significance. $\mathrm{P} \leq 0.05$ was considered significant.

Total score calculation: Scores were done for knowledge, attitude and practice questions as follows: The knowledge questions were scored as follows: Each question was scored (1) for correct answer, (0) for wrong answer and the total score for knowledge was computed for each subject. Four questions were used to measure knowledge. Question (1) had 4 correct answers. Question (2) had 12 correct answers; Question (3) had 3 correct answers. Question (4) had 8 correct answers. The range of score was "0 - 27". The total knowledge score was considered good if the score of the total knowledge ">50\%", while considered poor if it was " $\leq$ $50 \% "$.

The attitude questions were scored as follows: Each question was scored (2) for Agree answer, (1) for Neutral, (0) for Disagree answer except the question of using sun blocks, (0) for Agree answer, (1) 
Table (6): Scores of mothers' knowledge, attitude and practice towards vitamin $D$ and its supplementation:

\begin{tabular}{lrr}
\hline \multicolumn{1}{c}{ Score percentage/ categories } & Mean \pm SD & Number (\%) \\
\hline Knowledge score percentage & $40.56 \pm 15.93$ & \\
\hline Poor knowledge $(\leq 50 \%)$ & & $151(77.4)$ \\
Good knowledge $(>50 \%)$ & $44(22.6)$ \\
\hline Attitude score percentage & $74.27 \pm 14.87$ & \\
\hline Positive attitude $(\geq 75 \%)$ & & $123(63.1)$ \\
Neutral attitude $(50-<75 \%)$ & $67(34.4)$ \\
Negative attitude $(<50 \%)$ & $56.21 \pm 21.18$ & $5(2.5)$ \\
\hline Practice score percentage & & $91(46.7)$ \\
\hline Good practice $(\geq 75 \%)$ & $66(33.8)$ \\
Fair practice $(50-<75 \%)$ & $38(19.5)$ \\
Poor practice $(<50 \%)$ & & \\
\hline
\end{tabular}

for Neutral, (2) for Disagree and the total score for attitude was computed for each subject. Six questions were used to measure attitude. . The range of score was " $0-12$ ". The total attitude score was considered positive if the score was" $\geq 75 \%$ ", while considered neutral if it was "50 - <75\%", and considered negative if it was " $<50 \% "$. The practice questions were scored as follows: It was calculated according to the healthy practices by mother to improve her vitamin D level (Exposure to sun light, Eating food containing vitamin D, Taking vitamin D supplements). Each question was scored (1) for correct answer, (0) for wrong answer. For question asking about food, it was scored (0) for never, (1) for rarely, (2) for Sometimes and (3) for always. The range of score was " 0 - 5". The total practice score was considered good if the score of the total practices " $\geq 75 \% "$, while considered fair if it was "50- $<75 \%$ "and poor if it was " $<50 \% "$.

\section{Ethical Consideration}

Ethical committee board of Faculty of Medicine and administrative approval from the primary health care center manager were obtained. Informed consent was taken from each participant. The confidentiality of data was assured.

\section{Results}

The current study included 195 mothers who were recruited from El-Sherouk primary health care center in Cairo. The mean age of the mothers was $30.1 \pm 4.7$ years. More than half of the mothers (70.2\%) were in the age group (25-34 years). Less than half of the mothers $(40.5 \%)$ had two children the mean age of the children was $(22 \pm 17.3)$ months. Near half of the children (44.6\%) were in the age group (1-12 month). In addition, nearly three quarters $(72.3 \%)$ of the studied mothers with a bachelor's degree / Profession degree. More than half of the studied mothers $(51.8 \%)$ were house wives. Near two third $(63.1 \%)$ of them were living in their owned house. Regarding family income, $(51.8 \%)$ of the studied mothers reported that their families earn (1000 to 4000) EGP (Table 1).

About $(87 \%)$ reported that they have previously heard about vitamin D. Among them, $(62.4 \%)$ of mothers had received information about vitamin $\mathrm{D}$ from physician followed by media (46.5\%). Most of mothers $(90.6 \%)$ were aware of the role of vitamin $\mathrm{D}$ in bone 
Table (7): Factors affecting mothers' knowledge, attitude and practice score percentage

\begin{tabular}{|c|c|c|c|}
\hline Variables & $\begin{array}{c}\text { Knowledge score } \\
\text { percentage } \\
(\text { Mean } \pm \text { SD) } \\
\end{array}$ & $\begin{array}{l}\text { Attitude score } \\
\text { percentage } \\
(\text { Mean } \pm \text { SD) } \\
\end{array}$ & $\begin{array}{c}\text { Practice score } \\
\text { percentage } \\
(\text { Mean } \pm \text { SD) }\end{array}$ \\
\hline \multicolumn{4}{|l|}{ Mothers' age } \\
\hline less than 25 & $26.09 \pm 8.36$ & $62.70 \pm 14.34$ & $56.19 \pm 25.78$ \\
\hline $25-$ & $44.01 \pm 15.50$ & $77.69 \pm 11.98$ & $67.69 \pm 18.93$ \\
\hline $30-$ & $43.42 \pm 16.28$ & $75.46 \pm 16.00$ & $68.33 \pm 20.89$ \\
\hline 35 or more & $37.13 \pm 14.37$ & $72.52 \pm 14.55$ & $64.86 \pm 21.81$ \\
\hline $\mathbf{P}$ & $.000 *$ & $.001 *$ & .116 \\
\hline \multicolumn{4}{|l|}{ Mothers' education } \\
\hline Illiterate & $17.68 \pm 1.13$ & $65.55 \pm 11.73$ & $54.67 \pm 15.98$ \\
\hline School education & $29.88 \pm 10.33$ & $70.08 \pm 19.19$ & $60.00 \pm 25.13$ \\
\hline Higher education & $45.94 \pm 14.33$ & $76.36 \pm 13.24$ & $69.08 \pm 19.78$ \\
\hline $\mathbf{P}$ & $.000 *$ & $.004 *$ & $.005 *$ \\
\hline \multicolumn{4}{|l|}{ Family income } \\
\hline Less than $1000 \mathrm{LE}$ & $26.45 \pm 7.29$ & $70.83 \pm 14.86$ & $58.33 \pm 18.01$ \\
\hline 1000 to $2000 \mathrm{LE}$ & $34.56 \pm 14.85$ & $72.41 \pm 14.99$ & $64.14 \pm 22.71$ \\
\hline$>2000$ to $4000 \mathrm{LE}$ & $42.97 \pm 14.74$ & $77.90 \pm 15.31$ & $66.98 \pm 22.20$ \\
\hline More than4000LE & $45.60 \pm 15.76$ & $74.19 \pm 14.44$ & $68.29 \pm 19.86$ \\
\hline $\mathbf{P}$ & $.000 *$ & .250 & .384 \\
\hline \multicolumn{4}{|c|}{ Mothers' occupational status } \\
\hline Housewife & $34.7 \pm 13.75$ & $73.02 \pm 15.86$ & $61.39 \pm 21.77$ \\
\hline Working & $46.85 \pm 15.76$ & $75.62 \pm 13.68$ & $71.28 \pm 19.36$ \\
\hline $\mathbf{P}$ & $.000 *$ & .223 & $.001 *$ \\
\hline \multicolumn{4}{|l|}{ Housing status } \\
\hline Owned & $44.47 \pm 15.22$ & $76.29 \pm 13.99$ & $69.10 \pm 20.20$ \\
\hline Rented & $33.88 \pm 14.97$ & $70.83 \pm 15.76$ & $61.11 \pm 21.98$ \\
\hline $\mathbf{P}$ & $.000 *$ & $.013 *$ & $.011 *$ \\
\hline
\end{tabular}

health, enhance immunity by (38.9\%), healthy pregnancy by $(21.2 \%)$.However, $(2.9 \%)$ of the mothers did not know the benefits of vitamin $D$. Regarding the sources of vitamin $\mathrm{D}$, the highest correct sources identified by participants were milk and dairy products $(67.3 \%)$, egg yolk $(61.5 \%)$ and oily fish (52.9\%). However, $(59.6 \%)$ of participants identified incorrect sources (Table 2).

Regarding mothers' attitude; More than half of mothers $(56.9 \%)$ agreed with taking vitamin D supplementation during pregnancy and (61.5\%) of the mothers agreed with taking vitamin D supplementation during lactation. Less than half of mothers (47.2\%) agreed with using sun screen while exposing to the sun. About (69\%) agreed with doing a test to know level of vitamin D in the blood. More than three quarters of mothers (76.9\%) agreed with giving vitamin D supplementation to their children since birth. The majority of mothers $(90.3 \%)$ agreed with exposing their child to sun rays (Table 3 ).

Regarding mothers' practice; the majority of the participants $(81.0 \%)$ did not take vitamin D supplements. About one third of the mothers (33.3\%) responded "always" towards "taking vitamin D supplements during the last pregnancy". More than half $(54.9 \%)$ of the mothers never took vitamin D supplements during

Oct. 
lactation. Near half of the mothers $(49.7 \%)$ were always concerned that the food they are preparing containing vitamin $\mathrm{D}$ during the week. In addition, more than half of them $(53.5 \%)$ of them were exposed to the sun from 10 am to 3 pm. The exposure to the sunlight on average mean hours was $(4.0 \pm 5.7)$ hours weekly. Majority of them $(91.1 \%)$ spent more than one hour per week. Seventy two percent of mothers exposed their "face and arms" to the sun, while (44.6\%) never used sun screens (Table 4).

Regarding mothers' practice concerning their children; the majority of their children $(84.6 \%)$ were exposed to the sun. The parts of the body which were exposed to the sun as follows: (79.4\%) "Face" 69.7\% "Arms", 64.2\% "Legs", 10.3\% "Whole body". Thirty five percent of them were exposed to the sun from 10 am to 3 pm. The mean hours of exposure to the sunlight on average weekly was (3.6 \pm 5.6$)$ hours. Seventy two percent of the children were exposed to the sunlight more than one hour per week. Also, less than half of the mothers $(48.7 \%)$ gave their children vitamin D supplementation\& about half of them $(52.1 \%)$ started giving supplements since birth. Eighty nine percent of mothers gave them vitamin D supplements according to physician recommendation. Nearly half of mothers gave their children vitamin D drops regularly (Every day, $400 \mathrm{IU}$ or $600 \mathrm{IU}$ according to the age of the child). From those did not give vitamin D drops regularly, $(82.6 \%)$ of them was due forgetfulness (Table 5).

As regard the scoring of knowledge, attitude and practice of mothers; the mean percentage of knowledge score of studied mothers was 40.56 \pm 15.93 .About (23\%) had good knowledge towards vitamin D and its supplementation ( total knowledge score percentage $>50 \%)$.The mean percentage of attitude score of studied mothers was $74.27 \pm 14.87$.About $(63 \%)$ had positive attitude towards vitamin D and its supplementation (total attitude score percentage $\geq 75 \%$ ). The mean percentage of practice score of mothers towards vitamin $\mathrm{D}$ and its supplementation was $66.21 \pm 21.18$.About (47 \%) had a good practice towards vitamin $\mathrm{D}$ and its supplementation ( total practice score percentage $\geq 75 \%$ ) (Table 6).

Regarding factors affecting knowledge, attitude and practice scores; there was statistically significant association between mothers' age, different levels of education, occupation, housing status and family income and the mothers' knowledge. Mothers' attitude was significantly associated with mothers' age, different levels of education and housing status. Practice score was significantly associated with levels of education, occupation, housing status and family income $(\mathrm{P}<0.05)$ (Table 7).

\section{Discussion:}

Vitamin D deficiency is a worldwide epidemic and yet it is a problem that is largely unknown by majority of population. ${ }^{21}$ Regarding knowledge of mothers towards vitamin $D$ and its supplementation, in the current study, $(87.2 \%)$ of the participants reported that they have previously heard about vitamin D. Among them, (62.4\%) of mothers had received information about vitamin $\mathrm{D}$ from physician followed by media $(46.5 \%)$ \&family and friends (22.5\%).These findings is in agreement with Babelghaith et al., 2017 who conducted a study in Saudi Arabia \& found that the main sources of information about vitamin $\mathrm{D}$ were health care provider $(44 \%)$ followed by friends $(29.8 \%)$, and then media $(26.2 \%){ }^{22}$ This means that the health care provider is a good contributing factor to increase 
patient's sufficient knowledge of vitamin D because people report higher rates of intention to use vitamin D when they have been informed of the benefits via physician. The majority of mothers $(84.1 \%)$ were aware of sun rays as a source of vitamin $\mathrm{D},(61.1 \%)$ of them reported food sources, $17.1 \%$ reported supplementation and $4.7 \%$ didn't know any sources. These findings are similar to a study conducted by Babelghaith et al .,2017 who conducted a study in Riyadh, Saudi Arabia \& found that most of participants identified correctly the sun as a source of vitamin D (85\%) while a minor percentage of participants identified specific correct food sources. ${ }^{22}$

As regard health benefits of vitamin $D$, most of mothers (90.6\%) were aware of the role of vitamin $\mathrm{D}$ in bone health while a minor percentage of mothers identified specific vitamin $\mathrm{D}$ non-bone related functions. it is not surprising that mothers were less knowledgeable on the association between vitamin $\mathrm{D}$ and cardiovascular health, cognitive health, healthy pregnancy, prevention of cancer and diabetes, likely because these associations have been more recently identified (i.e., within the last several years) and have not necessarily been agreed on by all professionals .These results were similar to Babelghaith et al .2017 who found that almost all of participants $(91.3 \%)$ knew that vitamin D is vital for bone health, but less than half of participants believed that vitamin $D$ deficiency is related to other diseases. ${ }^{22}$ In contrast, Kavitha et al., 2015 found that only $(29 \%)$ of them were aware of vitamin $\mathrm{D}$ role in bone health and more than half of Indian mothers (52\%) didn't know the benefits of the vitamin D. ${ }^{23}$ This difference may be due to the majority of Indian mothers in the study were housewives $(86 \%)$ therefore they may be less knowledgeable than the employed women who have more access to internet, books and magazines as source of information in work area.

The results of the current study revealed that more than three quarters of the mothers $(77.4 \%)$ had Poor knowledge score $(<50 \%)$ towards vitamin D and its supplementation. This might be due to they didn't see doctors only if there was a problem in their infants and most doctors did not have enough time to discuss with mothers .This finding was supported by Kamal et al., 2017 who found that only $8.8 \%$ of Egyptian mothers had good knowledge about vitamin $\mathrm{D}$ and its deficiency. However $34.3 \%$ had average knowledge \& $56.9 \%$ of them had poor knowledge about vitamin D and its deficiency. ${ }^{24}$

Our study showed that $(56.9 \%)$ of mothers agreed with taking vitamin D supplementation during pregnancy and $(61.5 \%)$ of them agreed with taking vitamin D supplementation during lactation. Some mothers thought that multivitamin supplementation during pregnancy and lactation might have a harmful effect on the fetus and infant so that they have a negative attitude towards taking vitamin D supplementation.

Mothers had a positive attitude towards exposure to the sun light where around half of mothers $(52.8 \%)$ disagreed with using sunscreen while exposing to the sun light to benefit from it. Also, the majority of mothers $(90.1 \%)$ agreed exposing their children to the sun light.

Regarding vitamin D testing, about (68.7\%) of mothers agreed with doing a test know level of vitamin $\mathrm{D}$ in the blood. This finding was in agree with Babelghaith et al., 2017 who conducted a study in Riyadh, Saudi Arabia \& found that the majority of participants $(89.3 \%)$ were willing to do vitamin $\mathrm{D}$ test. This may be due to almost 
all participants (98.4\%) heard about vitamin $\mathrm{D}$ so they had a good attitude towards testing vitamin. ${ }^{22}$

Current study results showed that $(76.9 \%)$ of mothers agreed with giving vitamin D supplementation to their children since birth. Similar to Rasheed et al., 2016 who found that $75.25 \%$ of Iraqi mothers agreed that Vitamin D supplement is necessary to their infant. ${ }^{25}$

The current study revealed that more than three fifths of mothers had positive attitude regarding importance of vitamin $\mathrm{D}$ and its supplementation. This was in the same line with Kamal et al., 2017 who found that $64.4 \%$ of mothers had positive attitude regarding the importance of vitamin $\mathrm{D}$ and its supplementation. ${ }^{24}$

Our study revealed that (19\%) of mothers were taking vitamin D supplements. Similar to Habib et al., 2014 who stated that only $12.9 \%$ of Saudi females took vitamin D supplementation in his study. ${ }^{16}$ In the present study, about one third of the studied mothers took vitamin D supplementation regularly during pregnancy. In contrast to Kavitha et al., 2015 who found that none of mothers were taking vitamin D supplements during antenatal period. $^{23}$ Holick et al suggested that pregnant and lactating women require at least $600 \mathrm{IU} / \mathrm{d}$ of vitamin D and recognize that at least 1500-2000 IU/d of vitamin D may be needed to maintain a blood level of $25(\mathrm{OH}) \mathrm{D}$ above $30 \mathrm{ng} / \mathrm{ml}^{26}$

Regarding sun exposure practice of mothers, the majority of mothers $(80.5 \%)$ exposed to the sun when they were outside. While the correct recommended time for exposure of sun light is from 10 am to $3 \mathrm{pm}$, only about than half of the mothers $(53.5 \%)$ were exposed to the sun from 10 am to $3 \mathrm{pm}$ in the present study because they feared from dark complexion \& sun burn. Seventy seven percent of mothers exposed to the sun rays from one to six hours per week which is the recommended duration of exposure to the sun rays. Seventy two percent of mothers exposed their "face and arms" to the sun light. Near half of the mothers $(44.6 \%)$ never used of sunscreens. The current study results were opposite to Babelghaith et al., 2017 who found that less than half of Saudi females (46.4\%) exposed to the sun when they were outside. ${ }^{22}$ The reason behind this difference may be socio demographic and cultural differences because of limited sun exposure due to intense heat, cultural reasons for covering the body that makes sun exposure difficult. As regard sun exposure behavior of mothers towards their children, the majority of mothers $(84.6 \%)$ exposed their children to the sun, but only $(35.8 \%)$ of them exposed their children to the sun during the recommended time from 10 am to $3 \mathrm{pm}$ because most of mothers feared that sun rays are harmful during this time and also they don't know the right time to get vitamin D from the sun. (72.7\%) of them spent one to six hours per week according to the season, they exposed them longer duration in the winter, which is considered a good practice. Similarly, Cinar et al., 2006 who found that $87.5 \%$ of Turkish mothers exposed their infants on sunlight. ${ }^{27}$ Exposure to the sun is considered adequate for more than twice per week exposure of arms and legs which is equivalent to 20$25 \%$ body surface area between 10 am to 3 pm. $^{18}$

Regarding practice of mothers towards giving their children vitamin $D$ supplementation, Only (48.7\%) of the participated mothers gave their children vitamin D supplementation \& about half of them $(52 \%)$ started giving vitamin $D$ supplement to her children since birth because many of them were not aware that the supplementation was to be begun since birth. The mean age they started giving them vitamin D supplements was $(2.4 \pm 3.6)$ 
months. From those who did not give their children vitamin D drops regularly, (82.6\%) of them was due to forgetfulness. This finding was in agreement with Rasheed et al., 2016 who found that only (45\%) of the total participants were giving their infants vitamin D drops. ${ }^{25}$ American Academy of Pediatrics recommends giving infants who are exclusively breastfed or receive less than 1 liter of formula daily vitamin D supplementation (400 IU) daily, starting in the first few days of life. ${ }^{28}$

\section{Conclusions}

The current study found that the majority of study participants had limited knowledge, poor practices, but most of them had positive attitude towards benefits of vitamin D supplements. In addition, the study revealed inadequate exposure of mothers and their children to the sun light.

\section{Recommendations}

The study highlights the importance of Health education programs to mothers about the importance, sources, supplementation of vitamin D and the longterm effect of vitamin D deficiency and how to prevent. For physicians, Training program should be provided to improve their practice about vitamin D supplementation prescription and learn how to motivate mothers to be compliant on it.

\section{Study limitations}

There are some limitations to the study as it was conducted at primary health care center at El Sherouk city using convenience sampling technique; so, it is not representing all Egyptian mothers. Therefore, future studies should be conducted on larger sample size at different governorates in Egypt using better sampling technique to assure good representation of the target population. Another limitation, there may be some exaggeration in the recall of positive health behavior in an attempt to please the interviewer.

\section{References:}

1. Glerup, H., Mikkelsen, K., Poulsen, L., Hass, E., Overbeck, S., Thomsen, J., Charles, P., Eriksen, E.F. Commonly recommended daily intake of vitamin D is not sufficient if sunlight exposure is limited. Journal of Internal Medicine. 2000 Feb; 247(2):260-8.

2. Palacios, C., Gonzalez, L. Is vitamin D deficiency a major global public health problem? Journal of Steroid Biochemistry and Molecular Biology.2014 Oct; 144 Pt A: 138-45. doi: 10.1016/j.jsbmb.2013.11.003.

3. Vieth, R., Bischoff-Ferrari, H., Boucher, B.J., Dawson-Hughes, B., Garland, C.F., Heaney, R.P., et al. The urgent need to recommend an intake of vitamin $\mathrm{D}$ that is effective. American journal of clinical nutrition. 2007 Mar; 85(3):649-50.

4. Fuleihan, G. E. Vitamin D Deficiency in the Middle East and its Health Consequences. Clinical Reviews in Bone and Mineral Metabolism. Clinic Rev Bone Miner Metab. 2009; 7:77-9310.1007/s12018-009-9027-9

5. Sachan, A., Gupta, R., Das, V., Agarwal, A., Awasthi, P.K., Bhatia V. High prevalence of vitamin $\mathrm{D}$ deficiency among pregnant women and their newborns in northern India. American Journal of Clinical Nutrition. 2005 May; 81(5):1060-4

6. Dawodu, A., Wagner, C.L. Mother-child vitamin D deficiency: an international perspective. Archives of Disease in Childhood journal. 2007 Sep; 92(9):737-40.

7. Mrad, S.M., Gazdalli, N., Gharsallah, L., Bouyahia, O., Barsaoui, S., Boukthir, S., Sammoud, A. Study of 116 mothers of the knowledge, behavior, and practices of vitamin D supplementation. La tunisie Medicale journal. 2009 Apr; 87(4):273-

8. Aly, W.W., Hussein, M.A., Ebeid, S.M., Mortagy, A.K. Prevalence of vitamin D insufficiency among community dwelling elderly in Dakahlia as a representative of rural areas in Egypt. Aging, Clinical and Experimental Research. 2014 Feb; 26(1):47-51. doi: 10.1007/s40520-013-0139-1 
9. El Rifai, NM, Abdel Moety, GA, Gaafar, HM. Hamed, D.A. Vitamin D deficiency in Egyptian mothers and their neonates and possible related factors. Journal of MaternalFetal \& Neonatal Medicine. 2014 Jul; 27(10):1064-8. doi: 10.3109/14767058.2013.849240.

10.Cashman, K.D., Sheehy, T., O’Neill, C.M. Is vitamin $\mathrm{D}$ deficiency a public health concern for low middle income countries? A systematic literature review. European Journal of Nutrition. 2018 Jan 17. doi: 10.1007/s00394018-1607-3.

11.Kung, A.W, Lee, K.K. "Knowledge of vitamin $\mathrm{D}$ and perceptions and attitudes toward sunlight among Chinese middle-aged and elderly women: a population survey in Hong Kong”. BioMedCentral Public Health. 2006 Sep 7; 6:226.

12.Vu, L. H., van der Pols, J. C., Whiteman, D. C., Kimlin, M. G., Neale, R. E.(2010).Knowledge and attitudes about vitamin $\mathrm{D}$ and impact on sun protection practices among urban office workers in Brisbane, Australia. Cancer Epidemiology Biomarkers \& Prevention. 2010 Jul; 19(7):1784-9. doi: 10.1158/1055-9965.EPI-100127.

13.Christie, F.T. \& Mason, L. Knowledge, attitude and practice regarding vitamin D deficiency among female students in Saudi Arabia: A qualitative exploration .International Journal of Rheumatic Diseases .2011 Aug; 14(3):e22-9. doi: 10.1111/j.1756185X.2011.01624.x.

14.Bonevski, B., Bryant, J., Lambert, S., Brozek, I., Rock, V. The ABC of vitamin D: a qualitative study of the knowledge and attitudes regarding vitamin $\mathrm{D}$ deficiency amongst selected population groups. Nutrients. 2013; 5(3), 915-927.

15.Toher, C., Lindsay, K., McKenna, M., Kilbane, M., Curran, S., Harrington, L., Uduma, O. et al. Relationship between vitamin D knowledge and 25-hydroxyvitamin D levels amongst pregnant women. Journal of Human Nutrition and Dietetics. 2014; 27, 261-269.

16.Habib, F. M., Al-Motairi, W. A., Al-Mutairi, W. M. Vitamin D Deficiency :Knowledge and Practice among Adult Saudi Females. Global
Advanced Research Journal of Medicine and Medical Sciences. 2014; 3(5), 095-101.

17.Al Marzooqi, D., Al Ameri, D., Al Hayayi, E., Al Shehi, H., Al Ameri, K., Al Dhufair, K ., et al. Knowledge, attitude and practice of vitamin $\mathrm{D}$ supplementation status among six months old infants in Abu Dhabi Island $(\mathrm{N}=245)$. International Journal of Medical and Pharmaceutical Sciences. 2016; 6(5): 01-09

18.Botros, R.M., Sabry, I.M., Abdelbaky, R.S., Eid, Y.M., Nasr, M.S., Hendawy, L.M. Vitamin D deficiency among healthy Egyptian females.Endocrinology and Nutrition Journal .2015 Aug-Sep; 62(7):314-21. doi: 10.1016/j.endonu.2015.03.010.

19. World Health Organization. The known health effects of Ultraviolet radiation. World Health Organization. 2012. Available at: http://www.who.int/uv/faq/uvhealtfac/en/index 1.html

20.Holli, B.W. Circulating 25-hydroxyvitamin D levels indicative of vitamin D sufficiency: Implications for establishing a new effective dietary intake recommendation for vitamin D. The Journal of Nutrition. 2005 Feb; 135(2):31722.

21.Holick, M. F. \& Chen, T. C. Vitamin D deficiency: a worldwide problem with health consequences. The American Journal of Clinical Nutrition. 2008; 87:1080S-1086S.

22.Babelghaith, S.D., Wajid, S., Al-Zaaqi, M.A., Al-Malki, A.S., Al-Amri, F.D., Alfadly, S., et al. Knowledge and practice of vitamin D deficiency among people lives in Riyadh, Saudi Arabia-A cross-sectional study. Biomedical Research 2017; 28 (7): 3114-3118.

23.Kavitha, D., Anjalakshi, C., Venkataraman, P., Rukmani, J., Murali, R. Knowledge , Attitude and Practice regarding Vitamin D Deficiency among Antenatal Mothers in Tamilnadu. International Journal of Pharma and Bio Sciences. 2015 Oct; 6(4): (B) 486 - 497.

24.Kamal, W. K., El-Hamid, H. S., Abd ElGawaad, H .A., Mohy El-Deen, H .F. Mothers' Awareness regarding Vitamin D Deficiency among Their Infants in Qalyobia Governorate. Menoufia Nursing Journal. May2017; Vol.2, No. 1.

25.Rasheed, T.A., Taha, H.K., Rasheed, B.A. Knowledge, attitude and practice of Iraqi mothers towards Vitamin D supplementation to 
their infants in Baghdad Al -Rusafa 2016. AlKindy College Medical Journal. 2017; Vol.13 No.2 Page: $120-125$

26.Holick, M.F., Binkley, N.C., BischoffFerrari, H.A, Gordon, C.M., Hanley, D.A., Heaney, R.P. et al. Evaluation, treatment, and prevention of vitamin D deficiency: an Endocrine Society clinical practice guideline. The Journal of Clinical Endocrinology \& Metabolism. 2011:96, 1911-1930.
27.Cinar, N.D., Filiz, T.M., Topsever, P., Ucar, F., Akgul, S ., Gorpelioglu, S. Intentional sun exposure in infancy in Sakarya, Turkey. Saudi Medical Journal. 2006 Aug; 27(8):1222-5.

28. American Academy of Pediatrics and Pediatric Endocrine Society. 2017. Recommendations released on prevention, management of rickets. Available at: http://www.aappublications.org/news/2017/ 02/10/Rickets021017 